\title{
Integrating Speaking and Listening Activities into Teaching Anglo-American Academic Writing Rhetoric
}

\author{
Amir Kalan ${ }^{1}$ \\ ${ }^{1}$ Ontario Institute for Studies in Education, University of Toronto, Toronto, Canada \\ Correspondence: Amir Kalan, Language and Literacies Education Program (LLE), Ontario Institute for Studies in \\ Education of the University of Toronto, Toronto, ON, M5S 1V6, Canada. Tel: 1-647-346-4755. E-mail: \\ amir.kalan@mail.utoronto.ca
}

Received: December 7, 2013 Accepted: December 21, 2013 Online Published: December 22, 2013

doi:10.5430/ijelt.v1n1p101 URL: http://dx.doi.org/10.5430/ijelt.v1n1p101

\begin{abstract}
In an attempt to widen the range of practical strategies grounded in theoretical speculations of genre theorists, this paper proposes teaching the rhetoric of Anglo-American argumentation through pre-writing listening and speaking activities in ESL academic writing classes. Research shows students' struggles with ESL academic writing include more than inadequate knowledge of vocabulary, grammar, and sentence structure. Instead, the main problem is suggested to be a problem of rhetoric. Students' attachment to their native rhetorics and their unfamiliarity with Anglo-American academic rhetoric can seriously hinder the process of learning academic writing in English. Suggestions have been made that teachers should condition students into adopting Anglo-American rhetorical patterns through drills and controlled exercises. These methods, however, have proved unsuccessful, ignoring the impact of students' native rhetorics. Thus, an emphasis on paying sufficient attention to students' cultural backgrounds has been the focus of many recent studies, particularly among multiliteracies experts and genre theorists. This paper taps into the theoretical potential of the latter in order to propose integrating speaking and listening activities into teaching Anglo-American academic writing as a new strategy.
\end{abstract}

Keywords: contrastive rhetoric, intercultural rhetoric, L2 writing, ESL academic writing, genre theory

\section{Introduction}

In contrast with conversational proficiency, ESL (English as a second language) students might have to spend years (at least five and usually longer) to reach satisfactory academic proficiency in English (Cummins, 2007, p. 110). ESL academic writing, indeed, is an essential part of a student's academic fluency. Research shows students' struggles with ESL academic writing include more than inadequate knowledge of vocabulary, grammar, and sentence structure. Instead, the main problem is suggested to be a problem of rhetoric (Connor, Nagelhout, \& Rozycki, 2008). Students' attachment to their native rhetorics and their unfamiliarity with Anglo-American rhetoric can seriously hinder the process of learning academic writing in English. In order to teach Anglo-American academic writing rhetoric, most practitioners condition ESL students into adopting Anglo-American rhetorical patterns through drills and controlled exercises. These methods, however, have proved unsuccessful, ignoring the impact of students' native rhetorics. Thus, as will be discussed further in this paper, an emphasis on paying sufficient attention to students' cultural backgrounds has been the focus of many recent studies, particularly among multiliteracies experts and genre theorists. Yet unfortunately, although the conversation about the impact of native rhetorical tendencies on the quality of ESL academic writing has continued for decades, mainstream methods of teaching ESL writing reflect very little of the potentials of these discussions.

Harmonious with the scholarly literature that emphasizes the importance of students' cultural and rhetorical backgrounds, this paper offers a solution to this problem by suggesting explicit and critical teaching of Anglo-American argumentation rhetoric through speaking and listening exercises. This proposal is put forth based on my informal experiments with ESL writing students who I helped to familiarize themselves with Anglo-American rhetoric, before they actually started to write. Broadly speaking, the process my students experienced had two major steps. First, they analyzed English listening passages in order to identify Anglo-American rhetorical patterns. Second, they experienced guided oral debates with an imaginary audience with typical Anglo-American rhetorical 
expectations. Activities of this nature can meaningfully help ESL writers decode, discuss, and employ the rhetorical techniques commonly used in English academic writing.

\section{Theoretical Background}

\subsection{Kaplan's "Contrastive Rhetoric"}

A dramatic increase in the number of international students in post-war America attracted the attention of ESL researches to the challenges of teaching academic English writing to non-native speakers. Kaplan (1966) claimed that the problem of teaching ESL academic writing went beyond insufficient knowledge of vocabulary, grammar, and sentence structure. Kaplan urged ESL instructors to learn what sociologists and anthropologists had long known that language was a cultural phenomenon as well as a body of linguistic signs. Rhetorical traditions, in the same manner, are cultural and historical constructs. In other words, different cultures produce different rhetorical traditions; as a result, in order to learn writing in a new language, one has to learn a new rhetorical convention as well as a new language. Kaplan graphically represented different forms of paragraph development in some different cultures in the following sketches (Figure 1):
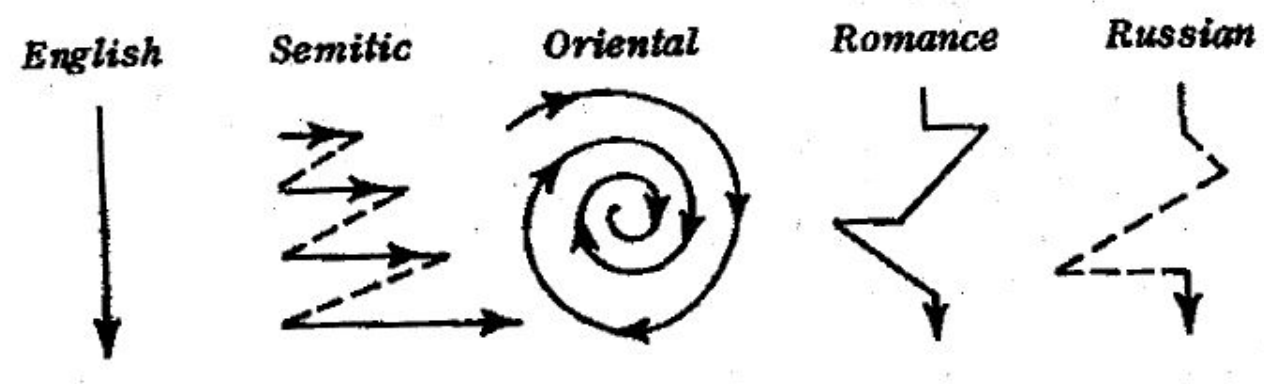

Figure 1. Kaplan's (1966) representation of different rhetorical traditions

Based on his description of rhetorical differences, Kaplan suggested a number of activities to fill the rhetorical gap between the English learner and English academic writing. These exercises include rearranging scrambled paragraphs, filling out an outline following given topic sentences, imitating models, filling in missing sentences, and composing by following an outline (Kubota \& Lehner, 2004). This reading of contrastive rhetoric advocated dismantling the English essay into small parts that students could learn through drills and exercises (Cummins, 2001). Thus, welcoming Kaplan's views, ESL instructors started to teach Anglo-American rhetoric by reducing the discourse to basic writing skills that could be taught in a hierarchical manner from simple to complex (Weaver, 1994). Kaplan's views, however, have been constantly critiqued and revisited. The following section contains some of the main concerns of Kaplan's critics.

\subsection{Criticisms of Contrastive Rhetoric}

The sweeping generalization of Kaplan's oversimplified doodles made his theory vulnerable to criticism. Critical pedagogists and poststructurally inclined theorists argued that neither was all English writing linear, nor were other cultures unused to harmony, unity, and organization when developing arguments. Some held that contrastive rhetoric was insensitive to cultural differences (Scollon, 1997) and some worried that it promoted the superiority of Western writing over Eastern rhetorical traditions (Kubota, 1999). Consistent with these views, the critics, generally speaking, agree that "despite its laudable pedagogical intentions to raise teachers' and students' cultural and rhetorical awareness in second language writing, traditional contrastive rhetoric has perpetuated static binaries between English and other languages and viewed students as culturally lacking" (Kubota \& Lehner, 2004, p. 7).

Although very interesting theoretical discussions, criticisms of Kaplan's "contrastive rhetoric" did not immediately translate into practical guidelines and actual activities in ESL textbooks and classroom practice. It was not until multiliteracists and genre theorists joined the conversation that some practical suggestions started to emerge. ESL instructors meanwhile continued with Kaplan's prescribed activities, which were basically designed to condition ESL students to write in the Anglo-American rhetorical tradition. However, although not very successful in changing teacher practices in the classroom, the critics now had posed a serious question: Will this conditioning process ever work if our students have rhetorical tendencies that have been solidly formed in other sociocultural circumstances? 
Will our students ever dispose of their own notion of "good writing" after going through "controlled exercises"? Or rather, should they do this at all?

Although Kaplan's critics demonstrate that students' native rhetorics and sociocultural backgrounds gravely impact teaching ESL writing, the practical strategies that can deal with and tap into a student's rhetorical world can be mainly found in multiliteracies and genre studies discussions. Multiliteracies experts suggest strategies that can help students display their literacies despite the language barrier, and genre theorists offer measures to introduce Anglo-American rhetoric to students as a genre, a new written medium that can translate their thoughts for a new readership. As a result of the clear distinction between these two approaches, there are significant differences between multiliteracies activities and genre strategies. Although multiliteracies activities smooth the path for a comfortable transition from mother rhetoric to alien rhetoric, they do not always invite students to consciously examine English academic writing as a genre. In view of the fact that the solution suggested in this paper falls in the category of genre theory, I will skip the literature penned by multiliteracies experts and briefly review the ideas of genre theorists.

\subsection{ESL Academic Writing and Genre Studies}

Although one can trace conversations about genres in written language back to the Greeks, and most prominently to Aristotle's Poetics, contemporary discussions about genre theory in literacy education were, to a considerable extent, inspired by Bakhtin's "The Problem of Speech Genres" (1986). Bakhtin in this article argues that written genres are constructed in communication and not merely in language. Moreover, he encourages inquiry into extraliterary genres such as legal writing and scientific writing. ESL writing instructors also have frequently experimented with teaching academic writing and business correspondence in English as a second language (Emilia, 2005; Cheng, 2008; Yang, 2012; Lai \& Tseng, 2012). In the English speaking world, genre investigations have led to three distinct genre movements that have examined genre theory in an ESL context (Hyon, 1996).

First, New Rhetoric research in the 1990's in North America speculated about writing with a focus on the situational contexts in which genres occur. Nevertheless, although they stated "[t]he more you understand the fundamental assumptions and aims of the community, the better able you will be . . . to evaluate whether the rhetorical habits you and your colleagues bring to the task are appropriate and effective" (Bazerman, 1988, p. 323), "direct translations [from theoretical analyses of social contexts and genres] into teaching are almost entirely absent" (Freedman \& Medway, 1994, p. 10).

Second, researches in ESP (English for specific purposes) have shown great interest in a genre approach to ESL writing in academic and professional settings. They regard genres as "communicative events" characterized both by "their communicative purposes" and by their "structure, style, content, and intended audience" (Swales, 1990, p. 58). When it comes to application, however, ESP theorists focus on the formal features dictated by a genre rather than the functions of the genre or the social context surrounding it (Hyon, 1996).

The third movement, the Australian Genre School, deals with secondary school education and tends towards practical applications. During roughly the same period as those of ESP and New Rhetoric studies, English-born Australian linguist Michael Halliday and his students, most notably Jim Martin, offered a teaching methodology for ESL writing which advocated a mastery of genre for student success in writing. The Australian genre theorists created a detailed model for ESL classroom instruction. They suggested that genre instruction should take place in three phases. The first phase is "modeling," in which the teacher presents text types and talks about (a) their "functions" (what the texts are for). Next, she demonstrates (b) the "schematic structure" of the text (how the information is organized). And finally, she focuses on (c) "lexico-grammatical features of the text" (the way the text speaks). The first phase thus is heavily concerned with questions of genre in order to help students put the linguistic texts they are to produce in the context of communication with an audience with certain stylistic expectations. In the next two phases, "joint negotiation of text" and "independent construction of text," students, either individually or collaboratively, create their own genre-specific texts (Hyon, 1996). Gibbons (2007), in another account of the experiments of the genre movement in Australia, describes four stages of a genre-oriented ESL writing process as (1) building knowledge of the topic, (2) modeling the text, (3) joint construction, and (4) independent writing. The strategy I propose in this paper fits into the "modeling" stage of the Australian school model, yet it differs from mainstream practice in the ways that I will discuss next.

\section{Discussion}

Although, as was discussed in the above review of literature, there has been much theoretical speculation about genre and ESL academic writing, it seems to be difficult to draw up a very long list of practical strategies that might help 
students feel more at ease with Anglo-American rhetoric. One can summarize all genre recommendations in three basic strategies.

1. Help students discover the arrangement of elements of an English essay through different activities. For example, ask students to put a scrambled essay back in the right order. Meanwhile, discuss the structure of an essay and ask why the genre in question demands such an organization. Or as another example, provide students with gap-filling exercises and ask them to choose the words or expressions that suit the register and voice dictated by the genre.

2. Encourage discussions about the genre of the writing task in hand (Rose, 2003). Ask what the purpose of writing the text is. Ask your students who will read the text. Encourage students to speculate about the style, register, and the structure of the text based on its purpose and audience.

3. Talk about the essay as an intellectual tool for critical thinking. Teach English academic writing forms as written media used for displaying higher-order thinking (Sharawy, 2011).

Although these are very useful strategies, they do not seem to be able to exploit all the potential offered by genre discussions. The advocates of the first group of activities with their puzzles and cloze tests focusing on style, register, and arrangement of the elements might run the risk of falling back into drills and control exercises, which, as has been already explained, have been criticized by multiliteracies experts and critical pedagogists. These are extremely useful exercises if students are already aware of the mechanisms of Anglo-American rhetoric and differences and similarities between the new rhetoric they are learning and their own native rhetorical tendencies.

When it comes to the second group of activities, which encourage discussions about the function and the audience of the text, ESL teachers should not assume that because their students do not have a good command of English, they do not know who the reader of a business letter, for example, is, or why we send an application letter to a university faculty. ESL students can be skilful essayists, meticulous letter writers, or brilliant poets in their own languages. Thus, it is not surprising that Rose's (2003) paper regarding this strategy is entitled "Teaching Students What They Already Know." Instead of asking a question as general as "why do we write a letter of complaint?" we might have to discuss what an American manager or faculty member looks for in a business or application letter and how it is different from the way a Chinese manager or faculty member, for instance, approaches a letter. This naturally again begs the question of which rhetoric each readership employs. And answering this question leaves us no choice but to familiarize our students with Anglo-American rhetoric as a unique intellectual entity different from the student's native rhetoric due to geographical, historical, political, and economic differences while emphasizing that neither Anglo-American rhetoric nor the student's native rhetoric is superior to the other.

In the same vein, assuming students are not capable of critical thinking, as the third strategy indicates, simply because they are ESL learners seems to be unfair. Instead, we can explore different forms of critical thinking, or in a more practical manner, different forms of looking at the world, collecting data, analysis, and presentation. In other words, we can briefly discuss different epistemologies with our students and tell them why Anglo-Americans process and present data the way they do.

As a result of these considerations, I suggest that, besides the activities recommended by genre theorists and practitioners so far, students need to take an additional measure in order to understand Anglo-American rhetoric more profoundly. I propose teachers engage students' speaking and listening skills so that students experiment with Anglo-America rhetoric in non-written forms as well as the actual writing task. This pedagogical measure can be regarded as a combination of practices informed by process writing theory and genre-oriented pedagogy (Hyland, 2003; Kim \& Kim, 2005).

Defining a paragraph as a thread of words around one single idea supported by particular examples is indeed very Anglo-American. In many other cultures, essays, for instance, are not as assertively opinionated as Anglo-American essays on account of the fact that traditionally other forms of writing have been used to express personal opinions in those cultures. Furthermore, some cultures encourage complex writing and they are not as strict as Anglo-American rhetoric about a single and clear theme or thesis harmonizing the whole piece. Similarly, relying on particular examples to prove a point is an Anglo-American approach based on the epistemological speculations of the British empiricists, philosophers such as Francis Bacon and David Hume.

The simple fact that Anglo-American rhetoric is a product of certain historical, social, and economic circumstances that have not been necessarily experienced by students who come from non-Anglo-American cultures should compel ESL teachers to help students consciously ponder upon this paradigm shift. To make such an attempt through speaking and listening, as recommended by this paper, can help students see Anglo-American rhetoric as a world 
view rather than meaningless formulas structuring English academic papers. The following lines roughly sketch the skeleton of a lesson plan with this purpose in mind.

First, students casually start a conversation about an assigned writing topic. The conversation flows with no teacher influence. When the first round of conversation is over, the teacher demonstrates how an English speaker might have talked about the same topic dictated by Anglo-American rhetoric. She also briefly talks about the historical and philosophical contexts which have given shape to Anglo-American rhetoric. At the end, students are asked to give their opinions about the same topic again, yet this time they are encouraged to translate their opinions into Anglo-American rhetoric. In crude terms, the arguments are required to be (a) opinions, (b) narrowed-down, and (c) exemplified (Bailey \& Powell, 1998). Second, students examine the art of argumentation in Anglo-American culture through listening exercises and compare it with the way arguments are delivered and supported in their own culture. Students listen to political speeches, chat show excerpts, and TV interviews and identify Anglo-American rhetorical strategies. An example of this activity is some kind of "listening cloze test" in which a listening passage is played and, when the main argument is made, is paused for the students to guess how the speaker would support that argument. Finally, having become conscious of the dynamics of Anglo-American rhetoric, students start a debate to convince an imaginary Anglo-American audience or the teacher as a member of the Anglo-American community.

This lesson sketch, however, is merely the skeleton of a strategy that could be fleshed out differently by different teachers and under different circumstances. The amount and manner of teacher feedback, peer feedback, team or group work might change in different variations of this strategy. Some variables, nevertheless, I hope will remain constant. These include (a) an emphasis on speaking and listening rather than writing, (b) employing authentic listening passages, (c) realistic conversations in order to genuinely elicit students' opinions, and (d) enough room for analysis of the student's native rhetoric along with a critical examination of Anglo-American rhetoric. With these ideas in mind any modification of this strategy that follows the following diagram (Figure 2) will be indeed congruent with the pedagogical targets discussed in this paper.

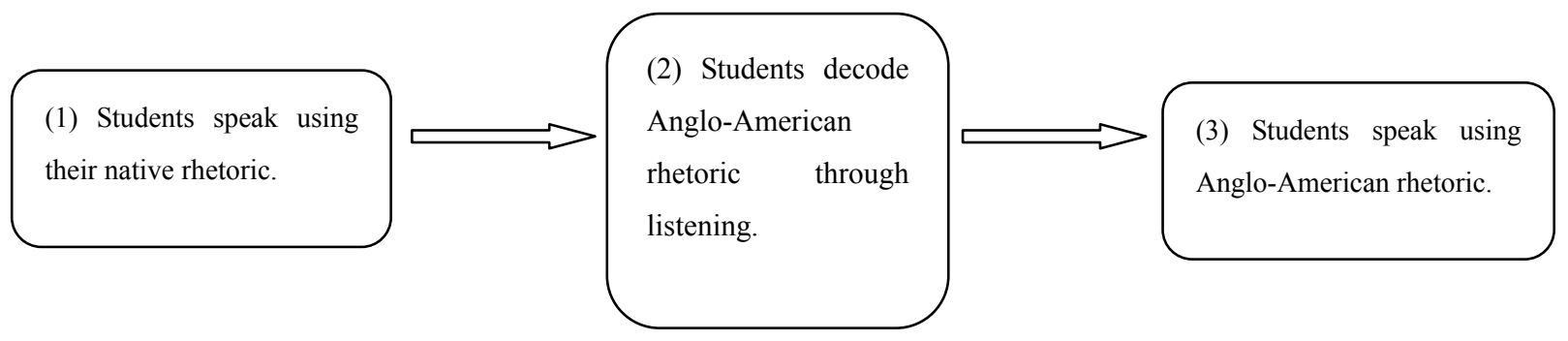

Figure 2. Arrangement of speaking and listening components

Using conversation to initiate a writing lesson is by no means a novelty. Multiliteracies experts and process writing theorists have frequently written about how pre-writing conversations can help ESL students find their voices, form their opinions, and brainstorm ideas (Zoellner, 1983). Likewise, listening exercises are increasingly employed in ESL textbooks to give students an insight into the context of the writing topics at hand and to provide students with the vocabulary needed. This paper, however, proposes that teachers employ speaking and listening exercises specifically for genre purposes so that students deepen their understanding of Angelo-American rhetoric. This suggestion hopefully will contribute to the repertoire of genre strategies developed to improve students' academic writing in English as a second language.

\section{Conclusion}

The problems of ESL writers tend to be reduced to issues of vocabulary, grammar, and sentence structure. However, dealing with intercultural (contrastive) rhetoric is in fact a higher priority. The practical measures recommended to help students make a rhetorical paradigm shift can be classified either as a multiliteracies activity or as a genre-related task. The strategy proposed in this paper belongs in the latter class rather than the former.

It, finally, should be emphasised that this attempt to widen the range of genre-related strategies in ESL academic writing is important because of two reasons. First, in comparison with multiliteracies studies, genre theory has taken less of a central role in classroom practice and scholarly literature regarding ESL writing in the past decade. Second, 
despite the noticeable amount of theoretical discussions about genre and non-literary texts, the list of practical measures to be offered to ESL writing teachers is relatively short. Hopefully, this paper will add an item to this list.

\section{References}

Bailey, E. P., \& Powell, P. A. (1998). The practical writer with readings (2nd ed.). New York: HOLT, RINEHART AND WINSTON, INC.

Bakhtin, M. M. (1986). The Problem of Speech Genres. In M. M. Bakhtin, Speech Genres and Other Late Essays (V. W. McGee, Trans.). Austin: University of Texas Press.

Bazerman, C. (1988). Shaping written knowledge: The genre and activity of the experimental article in science. Madison: University of Wisconsin Press.

Cheng, F. W. (2008). Scaffolding language, scaffolding writing: A genre approach to teaching narrative writing. Asian EFL Journal, 10(2), 167-191.

Connor, U., Nagelhout, E., \& Rozycki, W. V. (2008). Contrastive rhetoric: Reaching to intercultural rhetoric. Philadelphia: John Benjamins Pub.

Cummins, J. (2007). Language interactions in the classroom: From coercive to collaborative relations of power. In O. Garcia, \& C. Baker, Bilingual education: An introductory reader (pp. 108-136). New York: MULTILINGUAL MATTERS LTD.

Cummins, J. (2001). Negotiating identities: Education for empowerment in a diverse society (2nd ed.). Los Angeles, CA: California Association for Bilingual Education.

Emilia, E. (2005). A critical genre-based approach to teaching academic writing in a tertiary EFL context in Indonesia. Unpublished doctoral dissertation, The University of Melbourne, Melbourne, Australia.

Freedman, A., \& Medway, P. (1994). Locating genre studies: Antecedents and prospects. In A. Freedman, \& P. Medway (Eds.), Genre and the new rhetoric (pp. 1-20). London: Taylor \& Francis.

Gibbons, P. (2007). Writing in a second language across the curriculum. In O. Garcia, \& C. Baker, Bilingual education: An introductory reader (pp. 108-136). New York: MULTILINGUAL MATTERS LTD.

Hyland, K. (2003). Genre-based pedagogies: A social response to process. Journal of Second Language Writing, 12 , 17-29. http://dx.doi.org/10.1016/S1060-3743(02)00124-8

Hyon, S. (1996). Genre in Three Traditions: Implications for ESL. TESOL Quarterly, 30(4), 693-722. http://dx.doi.org/10.2307/3587930

Kaplan, R. (1966). Cultural thought patterns in intercultural education. Language Learning, 16(1), 1-20. http://dx.doi.org/10.1111/j.1467-1770.1966.tb00804.x

Kim, Y., \& Kim, J. (2005). Teaching Korean university writing class: Balancing the process and the genre approach. Asian EFL Journal, 7(2), 68-89.

Kubota, R. (1999). Japanese culture constructed by discourses: Implications for applied linguistics research and English language teaching. TESOL Quarterly, 33, 9-35. http://dx.doi.org/10.2307/3588189

Kubota, R., \& Lehner, A. (2004). Toward critical contrastive rhetoric. Journal of Second Language Writing, 13, 7-27. http://dx.doi.org/10.1016/j.jslw.2004.04.003

Lai, S., \& Tseng, M. L. (2012). Genre analysis of requesting letters in business language textbooks and the workplace. The Asian ESP Journal, 8(3), 5-27.

Rose, J. M. (2003). Teaching Students What They Already Know: Student Writers as Genre Theorists. Issues in Writing, 14(1), 25-44.

Scollon, R. (1997). Contrastive rhetoric, contrastive poetics, or perhaps something, else? TESOL Quarterly, 13, 352-363. http://dx.doi.org/10.2307/3588051

Sharawy, K. (2011). It Is All About Critical Thinking. Retrieved April 20, 2012, from TESL Ontario Online Professional Development (PD): http://www.snwebcastcenter.com/custom_events/tesl-2011-fpp/site/player_ archive.php

Swales, J. M. (1990). Genre analysis: English in academic and research settings. Cambridge: Cambridge University Press. 
Weaver, C. (1994). Reading process and practice: From sociolinguistics to whole language (2nd ed.). Portsmouth, NH: Heinemann.

Yang, W. (2012). A study of students' perceptions and attitudes towards genre-based ESP writing instruction. The Asian ESP Journal, 8(3), 50-73.

Zoellner, R. (1983). Talk-write: A behavioral pedagogy for composition. In M. Myers, \& J. Gray (Eds.), Theory and practice in the teaching of composition: Processing, distancing and modeling (pp. 122-128). Urbana, IL: National Council of Teachers of English. 